\title{
Offener Brief der Schweizerischen Gesellschaft für Orthopädie und Traumatologie an den Präsidenten der FMH
}

Sehr geehrter Herr Präsident

Mehr denn je sind wir überzeugt, dass die Führung der FMH eine Vielzahl an Qualitäten und Kompetenzen erfordert, wobei Objektivität und insbesondere Unparteilichkeit die Führungspersonen auszeichnen müssen. Diese Qualitäten sind unverzichtbar für die Vertretung der gesamten Ärzteschaft, unabhängig von Meinungen und Einstellungen.

Mit Ihren eindeutigen Stellungnahmen und Bekundungen Ihrer politischen Orientierung, die in jüngster Zeit durch die Medien gegangen sind, verfolgen Sie Ambitionen auf ein politisches Amt auf höchster Ebene. Wir beabsichtigen nicht, Ihnen dieses Recht abzusprechen, doch verstehen Sie bitte unsere Sorge, dass die künftige Ausrichtung und Arbeit der FMH unter dem Einfluss eines Präsidenten stehen wird, der sich offen zu Thesen einer Partei bekennt, deren gesundheitspolitische Richtung häufig im Widerspruch zu den Interessen der Mitglieder dieser Gesellschaft steht.

Der Vorstand der SGOT-SSOT vertritt einstimmig die Auffassung, dass die beiden Ämter absolut unvereinbar sind. Sie werden als Nationalrat nicht mehr in der Lage sein, die Interessen der gesamten Schweizer Ärzteschaft loyal und unparteiisch zu vertreten. Die Ambiguität zwischen der Führung der FMH und Ihrem politischen Engagement führt zu einem inakzeptablen Interessenkonflikt. Sollten Sie Ihre Kandidatur auf einen Sitz im Nationalrat aufrechterhalten, fordern wir Sie daher in aller Form auf, Ihr Amt als Präsident der FMH niederzulegen.

Hochachtungsvoll

Im Namen des Vorstands der SGOT-SSOT: Prof. Dr. med. Christian Gerber, Präsident; Dr. med. Bernhard Christen, Vize-Präsident

\section{Antwort des Präsidenten der FMH}

Liebe Kolleginnen und Kollegen

Besten Dank für Ihr Schreiben und Ihre Stellungnahme. Diese gibt mir die Gelegenheit, mich erneut zu dieser wichtigen Frage zu äussern.

Der zentralen Aussage Ihres Schreibens kann ich nur beipflichten: Wie der Vorstand der SGOT und der FMH-Zentralvorstand bin auch ich ganz klar der Überzeugung, dass für das Amt des FMH-Präsidenten Objektivität und Unvoreingenommenheit unabdingbar sind. Diesen Grundsatz teile ich ohne jeden Vorbehalt.

Zudem schreiben Sie, dass die Positionen der Sozialdemokratischen Partei im Widerspruch zu den Auffassungen der FMH ständen. Tatsächlich werden die Interessen der Ärzteschaft in der Schweiz jedoch von keiner der politischen Parteien vollumfänglich vertreten - weder von den Sozialdemokraten noch von den bürgerlichen Parteien. Um einige Beispiele zu nennen, erinnere ich an die Position der bürgerlichen Parteien bei der Abstimmung über den Verfassungsartikel 117a im Jahr 2008 oder bei der Frage der freien Arztwahl (Kontrahierungszwang) und bei der Beschränkung des Leistungskatalogs.
Abgesehen davon sind die Prioritäten völlig klar: Von Anfang an habe ich öffentlich erklärt, dass ich keine Positionen vertreten werde, die im Widerspruch $\mathrm{zu}$ den Positionen der FMH stehen, welche ja von deren statutarischen politischen Gremien festgelegt werden.

Für die Ärzteschaft ist es zweifellos wichtig, dass sie in der Gesellschaft aktiv vertreten ist und sich am gesellschaftlichen Diskurs beteiligt. Sie muss ihre spezifischen Standpunkte direkt einbringen und an den Diskussionen über unser Gesundheitswesen teilnehmen. Wir können die Interessen und Ziele der Ärzteschaft nicht vertreten, ohne auch politisch zu werden! Auch die aktuellen Vizepräsidenten der FMH sind politisch engagiert - und zwar bei einer anderen Partei, der freisinnig-demokratischen Partei. Und bekanntlich sind zur Zeit sowohl der Präsident von $\mathrm{H}+$ wie auch der Präsident von santésuisse Mitglieder des Parlaments. Doch in den eidgenössischen Räten findet man heute keinen Arzt, der ausdrücklich und in erster Linie die Anliegen der Ärzteschaft vertreten will.

Zudem macht ein Blick auf die politische Landschaft - gerade in der Gesundheitspolitik - und auf 
die politischen Auffassungen innerhalb des Zentralvorstands der FMH deutlich, dass meine Nationalratskandidatur weder die politischen Optionen der FMH noch deren Ausgewogenheit beeinträchtigt. Sie wird es erlauben, den Einfluss der Ärzteschaft auf alle politischen Fragen besser und ausgewogen geltend $\mathrm{zu}$

\section{Keine Gesundheitspolitik ohne die FMH!}

Die Ärzteschaft verschafft sich Gehör in gesundheitspolitischen Belangen - so lautet einer der Aufträge aus der Ärztekammer vom Mai 2008, welchen die Mitglieder des FMH-Zentralvorstandes in die vierjährige Legislaturperiode mitgenommen haben. Sie sollen den politischen und gesetzgeberischen Prozess konsequent mitprägen und die Interessen der Ärzteschaft in allen relevanten Gremien aktiv vertreten. «Keine Gesundheitspolitik ohne die $\mathrm{FMH}$ !» ist deshalb zentraler Bestandteil der strategischen Ausrichtung der FMH und Leitsatz der Mitglieder des Zentralvorstandes.

Die Ärzteschaft muss sich in die Politik einbringen, wenn sie heute und in Zukunft das Schweizer Gesundheitswesen mitgestalten will, wenn sie machen und unserer Stimme in den Debatten, die uns direkt betreffen, mehr Gehör zu verschaffen.

Mit freundlichen Grüssen

Dr. med. Jacques de Haller, Präsident der FMH

die Attraktivität ihres Berufes erhalten und eine qualitativ hochstehende medizinische Versorgung für Patientinnen und Patienten sichern will.

Dank dem konsequenten politischen Engagement des Zentralvorstandes und der FMH-Gremien ist die Verbindung der Schweizer Ärztinnen und Ärzte zu einem wichtigen Akteur in der Gesundheitspolitik geworden. Im Sinne des Auftrags der Ärztekammer ist es deshalb zu begrüssen, dass die Mitglieder des Zentralvorstandes und weitere standespolitisch tätige Ärztinnen und Ärzte auf Ebene der Gemeinden, in kantonalen und nationalen Gremien politisch vertreten sind und die Anliegen der Ärzteschaft in die Gesundheitspolitik einbringen.

Zentralvorstand der FMH, März 2011 